\title{
INDIVIDUALISMO Y COLECTIVISMO EN EL ANÁLISIS SOCIOLÓGICO
}

\author{
Rafael Gobernado Arribas \\ Universidad de Málaga \\ E-mail: gobernado@uma.es
}

\begin{abstract}
RESUMEN
La disyuntiva individualismo versus colectivismo es una de las muchas disyuntivas que se entrecruzan en la confección del mapa social. Para destacar la complejidad que entraña la misma, se ha elaborado un conjunto de conceptos organizados alrededor de la noción de individualismo, en los tres niveles tradicionales de análisis sociológico: el social, el de la cultura y el de la personalidad. En cada uno de tales niveles se han buscado, a su vez, los conceptos complementarios y los contradictorios a los propiamente individualistas, dando lugar a una clasificación conceptual compleja y útil.
\end{abstract}

En la búsqueda de una definición convincente de lo que se entiende por sociedad se llega inevitablemente a dos tradiciones sociológicas difícilmente casables: la aristotélica o colectivista y la iusnaturalista o individualista ${ }^{1}$. Se pretende presentar en el texto que sigue una definición de sociedad que abar-

La disyuntiva citada, colectivismo versus individualismo, no es el único escollo con el que se encuentra la búsqueda de una definición del término «sociedad». Existen muchas otras disyuntivas teóricas también problemáticas; así: macro versus microsociología; orden versus conflicto; objetivismo versus subjetivismo; monismo versus pluralismo metodológico; positivismo versus teoría dialéctico-crítica; neutralidad versus compromiso, etc. El fundamento de los distintos paradigmas sociológicos se encuentra en las diferentes opciones tomadas por los autores en cada una de las disyuntivas enumeradas arriba. 
que ambos puntos de vista, el individualista y el colectivista, entendiendo por punto de vista individualista tanto el que se preocupa por las consecuencias sociales de la acción cuanto el que se preocupa por los condicionamientos sociales de la acción; y entendiendo por punto de vista colectivista tanto el "comunitario", o sea, el que resulta de una comunión en el sentido que Durkheim dio a este término en su magistral obra Las formas elementales de la vida religiosa, como el cooperativo.

Paradójicamente, para alcanzar esa definición de «lo social» comenzaremos por exponer los usos que ha recibido en la teoría sociológica el término «individualismo", para luego, paso a paso, ir completando el mapa de lo social, mediante el artificio de precisar los conceptos contrarios al individualismo.

En efecto, para desarrollar nuestra tipología se han distinguido dos clases de conceptos contrarios: $1 .^{\circ}$ ) los complementarios, y 2. ${ }^{\circ}$ ) los contradictorios. Dos conceptos son complementarios cuando su suma forma una «clase». Por su parte, dos conceptos son contradictorios cuando uno implica la negación del otro (del tipo de «si $a$, entonces no $b$ », siendo $a$ y $b$ los conceptos).

Los conceptos complementarios correspondientes, así como las dicotomías complementarias oportunas, se agrupan bajo la dicotomía genérica: individualismo versus cooperación. Por su parte, los conceptos contradictorios y sus respectivas dicotomías se agrupan, a su vez, en la también genérica: individualismo versus comunión. La suma de los tres tipos de conceptos (es decir, los correspondientes al individualismo, sus complementarios y sus contradictorios) permite una visión más completa del comportamiento humano desde la Sociología.

\section{NIVELES DE ANÁLISIS DEL INDIVIDUALISMO}

El término "individualismo» se usa en Sociología indistintamente en tres niveles diferentes de análisis, cosa que lleva consigo muchas posibilidades de equívoco. El interés de la presente reflexión descansa en gran medida en la pretensión de poner en evidencia tales niveles diferentes de análisis y evitar, en lo posible, las confusiones que tal uso origina ${ }^{2}$.

Un nivel de los indicados es el metodológico, de acuerdo con el cual, como se sabe, el axioma básico en el que se apoyan los modelos explicativos del acontecer social consiste en la afirmación de que todos los individuos que forman la sociedad son igualmente racionales e intercambiables: actúan buscando su propio beneficio después de un análisis de costes y beneficios de su propia acción.

2 Conscientes del mismo problema, P. Birnbaum y J. Leca (1990) distinguen, por su parte, tres tipos de realidades a las que se pueden referir los sociólogos al hablar de «individualismo». Primero, el individualismo en cuanto rasgo que define una conducta, una institución o una sociedad. Segundo, el individualismo como elemento que forma parte de un proceso de legitimación fundamentalmente política. Por último, el individualismo como axioma metodológico (p. 3). Ciertamente, existe un paralelismo con la clasificación propuesta por nosotros. 
De tal axioma, al igual que de cualquier otro, no se puede decir que sea verdadero o falso (todos los axiomas, por definición, gozan de ambas cualidades a la vez), sino que es más o menos útil para explicar el acontecer social. A su vez, tal utilidad viene definida estadísticamente. La aceptación de uno u otro axioma es la base del desarrollo de los paradigmas científicos o escuelas teóricas ${ }^{3}$.

Un segundo nivel es el ideológico. En este caso, el individualismo es una de las justificaciones más importantes que guían la toma de decisiones, tanto en el colectivo (el Estado en último extremo) como en los sujetos que forman esas colectividades. Se trata, en realidad, de una explicación que las personas se dan a sí mismas, generalmente a posteriori, para legitimar su comportamiento y el de los demás. Bajo esta ideología individualista cabe la aceptación del sistema de mercado y de la libre empresa como forma óptima de organización económica, por ejemplo. Al igual que con los axiomas, tampoco se puede decir de las ideologías que sean verdaderas o falsas, sino que están más o menos aceptadas por la población.

El tercer nivel es el más próximo al hombre objeto de estudio; podríamos llamarlo nivel de la realidad: ¿se comporta el hombre siguiendo criterios individuales en verdad o, por el contrario, se trata de un ser sumamente gregario? La respuesta a esta pregunta es problemática, ya que la realidad sólo es posible observarla a través de los ojos de la ideología o, en el mejor de los casos, a través de los ojos del método científico. Para obviar este problema, ahora partiremos de la idea de que la realidad alberga todas las posibilidades lógicas, es decir, tanto las esperadas ideológica y metodológicamente como las emanadas de sus "contrarios». Precisamente esta sospecha lógica es la que nos va a ayudar a desenmarañar el enredo inicial en los tres niveles considerados.

Precisando algo más, se debe apuntar que cada uno de los niveles anteriores, objeto todos ellos de estudio por parte de la sociología (aunque no exclusivamente de ella), pertenecen a sendos niveles de análisis del comportamiento humano: el social, el cultural o ideacional y el de la personalidad, respectivamente. Según esto, el individualismo metodológico constituye una de las variadas formas de entender el sistema social; la ideología individualista define en último extremo un sistema cultural, y el ser o no individualista constituye uno de los rasgos de la personalidad. No es éste el momento de resaltar las mutuas implicaciones de estos tres niveles, en particular durante el proceso de socialización, de sobra conocidas por los sociólogos.

\section{INDIVIDUALISMO VERSUS COOPERACIÓN}

En cada uno de los niveles considerados (el del sistema social, el de la cultura y el de la personalidad) se pueden observar dos niveles básicos, opuestos

${ }^{3}$ Entre la abundante bibliografía crítica sobre el alcance del individualismo metodológico merece destacarse a R. H. Turner (1991). 
aunque complementarios. Puesto que se trata de conceptos complementarios, no constituyen antítesis en el más profundo sentido del término. Cada uno de los extremos propuestos pueden englobarse en la disyuntiva «individualismo» versus "cooperación»" Tales conceptos complementarios no agotan en absoluto la descripción del nivel correspondiente.

En el sistema social se contraponen los conceptos de actor y estructura social. Por estructura social se entiende, ahora, la organización del sistema social emanada de la división social del trabajo. Todos los sistemas sociales implican, por lo tanto, una estructura social. Lo que diferencia unos sistemas de otros es el grado de complejidad de tal estructura. A mayor complejidad, los actores dispondrán de un abanico más amplio de alternativas en que escoger. De cualquier forma, ninguna estructura social impide por completo el ejercicio de la toma individual de decisiones para actuar. Se ha denominado "estructuralismo" a la corriente teórica en la que prima la estructura social a la hora de explicar el comportamiento humano, mientras que se denomina «teoría de la acción» la corriente que da prioridad al actor individual.

En el nivel ideacional, los conceptos complementarios son los de ideología que apoya a la sociedad civil (liberalismo) e ideología que apoya al Estado (estatalismo, colectivismo o socialismo). Entendemos por sociedad civil el resultado organizacional del libre juego de los intereses individuales (privados). Por el contrario, el Estado, en principio, pretende un resultado organizacional basado en el interés colectivo mediante el ejercicio legítimo de la coacción. Las ideologías colectivistas pretenden conseguir más fuerza para el Estado, mientras que las liberales pretenden lo propio con la sociedad civil.

En el nivel de la personalidad, los conceptos complementarios son los de conciencia del "yo" y conciencia del «nosotros». La noción de personalidad utilizada generalmente por los sociólogos suele reducirse a esta simple bipolaridad. En el primer caso, el individuo toma las decisiones orientado por una estrategia individual de comportamiento (individuo "egoísta»); mientras que en el caso del individuo con conciencia del "nosotros» su estrategia es colectiva, actúa de acuerdo con los intereses del grupo (individuo "altruista»). En ambos casos el individuo busca su propio beneficio, directa o indirectamente.

Tales conceptos complementarios, los seis repasados hasta aquí, tienen en común, no obstante, el pertenecer a una concepción racional de la sociedad; a una concepción racional del comportamiento humano. Se entiende que un

${ }^{4}$ Los economistas tienden a distinguir dos tipos también complementarios de bienes y servicios, distinción directamente emparentada con la de individualismo y cooperación: por un lado, hablan de bienes y servicios que se intercambian, se venden; y, por otro, hablan de bienes y servicios que se proporcionan. En el primer caso, el conseguirlos es cuestión de intercambiar el precio por el producto o servicio. En el segundo, todos los individuos pertenecientes a determinada categoría social tienen igualmente acceso al producto o al servicio con independencia de su aportación al esfuerzo común (por ejemplo, el uso de las carreteras, de la sanidad pública o de la educación también pública). La existencia del primero depende de la aportación individual; la del segundo, de la cooperación. Véase A. de Jasay (1989). 
comportamiento es racional cuando reúne dos cualidades: la primera consiste en que los medios se adecúen a los fines, y la segunda en que los fines pertenezcan a un sistema congruente de preferencias 5 . No todo comportamiento pertenece a esta categoría, como es obvio, aunque, a diferencia de lo sospechable, es posible que la mayoría de comportamientos sea racional (así, por ejemplo, el comportamiento tradicional, la rutina, las lealtades, etc., tienen mucho que ver con la racionalidad). Antes de continuar vale la pena recapitular mediante el siguiente esquema clasificatorio.

Conceptos lógicamente complementarios según niveles de análisis

\begin{tabular}{lcc}
\hline & Individualismo & Cooperación \\
\cline { 2 - 3 } Sociedad & Actor & Estructura social \\
Cultura & Liberalismo & Colectivismo \\
Personalidad & "Yo» & "Nosotros» \\
\hline
\end{tabular}

\section{INDIVIDUALISMO VERSUS COMUNIÓN}

Corresponde ahora dar un nuevo paso en la complejidad del análisis. Se trata de buscar los conceptos contradictorios a los correspondientes del individualismo, en cada uno de los niveles enunciados; así como destacar las diferencias entre complementariedad y contradicción entre las sucesivas propuestas, entendiendo las disyuntivas complementarias como disyuntivas "falsamente colectivistas» desde un punto de vista teórico.

\subsection{EL MÉTODO: ACTOR VERSUS RELACIÓN}

Dos son las formas tradicionales de considerar la sociedad: por un lado, se trata de una realidad objetivada, externa al individuo, ya construida y que condiciona el comportamiento de los individuos; por otro, la sociedad es una realidad que se encuentra en constante proceso de producción por parte de actores y cuyo análisis se centra en las consecuencias, esperadas o no, del comportamiento de tales actores. El individualismo metodológico pertenece a esta categoría sociológica. A la otra categoría se la ha denominado estructuralismo, como ya se dijo.

Sin embargo, a poco que repasemos la producción sociológica de autores que defienden una u otra postura, se descubrirá que no existe una auténtica confrontación entre ambas posiciones. Por el contrario, se trata de acepciones totalmente complementarias cuyo análisis conjunto no plantea ningún proble-

5 Para una definición más completa de «racionalidad», véase E. Gellner (1990). 
ma de lógica interna ${ }^{6}$. El análisis propio del individualismo metodológico no sólo puede, sino que tiene que desarrollarse a partir de categorías sociológicas objetivadas y externas a los actores, es decir, propias de un enfoque estructuralista, tales como «clase social», «estrato» o «rol». Se trata en estos casos de tener en cuenta los condicionamientos relativos del comportamiento humano, comportamiento que en ningún caso deja de tener un margen de libertad de elección que permite el surgimiento de las estructuras espontáneas no previstas. No es posible pensar en un actor totalmente en el vacío. Como complemento, explicar el comportamiento humano condicionado por la estructura social, dejando a un lado la toma de decisiones de los actores, conduce a una visión «mágica» de la sociedad, ya que supondría establecer una ligazón inmediata entre fenómenos obviamente lejanos ${ }^{7}$. El hecho de que el actor pueda ser tanto una persona física como jurídica termina de poner en entredicho la visión estrictamente individualista del modelo teórico.

Otra disyuntiva también falsa es la que se establece entre individualismo (guiado por la acción motivada de los actores) y funcionalismo ${ }^{8}$ (explicación teleológica, aparentemente cegada para los actores), disyuntiva paralela a la que

6 El libro clave para comprender el «individualismo metodológico» en Sociología sigue siendo el de R. Boudon (1981). De acuerdo con este autor, la Sociología que emana de tal planteamiento teórico se apoya en tres proposiciones básicas: primera, existe una estructura del sistema de interacción que constituye el marco dentro del cual se explican los comportamientos sociales; segunda, la unidad de análisis es el actor individual, que actúa dentro de un contexto con mayor o menor capacidad de maniobra; tercera, tal acción es de naturaleza compleja, a diferencia de la tenida en cuenta por los economistas, cuya lógica es demasiado simple. La complejidad de tal acción es matizada en una obra anterior del mismo autor. Distingue R. Boudon (1979) cuatro tipos de modelos explicativos de corte individualista en función de su complejidad: 1) El marxiano, en el que las acciones respectivas de los actores son independientes; el actor, además, no tiene en cuenta los efectos de su acción sobre los otros; las preferencias del actor son consideradas variables independientes que no necesitan explicación, que se dan por supuestas (ej., la teoría del beneficio de Marx). 2) El modelo tocquevillano, en el que las preferencias se explican por su pertenencia a un sistema social; los individuos se comportan de acuerdo con criterios culturales o ambientales; no obstante, la acción sigue siendo individual (ej., "la profecía que se cumple a sí misma" de Merton). 3) El modelo mertoniano, en el que, a partir de una decisión individual, un conjunto de individuos convergen "molestándose» recíprocamente (ej., la explicación de P. Blau de la crisis universitaria de los años sesenta). 4) El modelo weberiano, el más complejo, que tiene en cuenta los diferentes elementos de la acción, los factores determinantes exteriores y los anteriores de la acción (ej., el análisis de B. Bernstein del fracaso escolar).

7 La necesidad de un análisis conjunto de la estructura social y del actor puede ser la causa de la doble interpretación que ha sufrido el pensamiento de Durkheim: para unos, es el precursor del colectivismo u holismo y del determinismo; para otros, lo que interesaba a Durkheim eran los sistemas concretos de interacción que definen las instituciones para los agentes sociales. Parsons, Alpert y Boudon son algunos de los autores que hacen esta última lectura. Sobre ello, véase J. del Pino Artacho (1990: 96-98).

${ }^{8}$ Véase al respecto a J. E. Rodríguez Ibáñez (1991). Repasa el autor la obra de, entre otros, J. Elster y la propuesta implícita en la misma de una organización teórica global de la acción intencional, en absoluto contradictoria con una realidad institucional «fruto del entrecruzamiento de acciones intencionales» (p. 28). Coinciden los autores con R. Boudon en que la acción considerada por la Sociología es de naturaleza más compleja que la considerada por los economistas. 
se da entre individualismo y evolucionismo. La falsedad proviene del primitivo desarrollo de los modelos del individualismo metodológico, sumamente simples y en los que no se tenía en cuenta, por ejemplo, la iteración, el aprendizaje, etc. Es posible, por lo tanto, que aplicando la racionalidad individual dentro de un proceso más o menos largo de experiencia continuada se llegue a adoptar decisiones individuales cuya racionalidad sea a largo plazo, es decir, sea una racionalidad colectiva (o funcionalismo) ${ }^{9}$. La propia racionalidad individual puede conducir a mantenerse dentro de las más estrictas normas de la tradición y del grupo ${ }^{10}$.

La forma verdaderamente distinta, contradictoria, al individualismo metodológico de entender el sistema social consiste en olvidarse del actor y centrar el análisis en la relación entre actores. No abundan en Sociología los análisis relacionales macrosociológicos debido a las dificultades que plantean, limitándose a los niveles micro. Pertenecen a este género relacional todos aquellos paradigmas basados en la interacción, del tipo de la sociología fenomenológica, el interaccionismo simbólico, o la teoría del intercambio social en su versión antropológica de M. Mauss. La técnica de análisis (que no paradigma) de redes sociales, el sociograma de L. Moreno y la teoría matemática de los grafos, entre otras técnicas, parecen proporcionar el método idóneo para el salto desde la interacción cotidiana a la sociedad global dentro del análisis relacional. Es obvio que el paradigma relacional es el verdaderamente colectivista, metodológicamente hablando, ya que cualquier relación exige al menos dos individuos.

\subsection{LA IDEOLOGÍA: ARISTOTELISMO VERSUS IUSNATURALISMO}

Habitualmente se ha venido contraponiendo la ideología que apoya al individuo frente a la ideología que apoya al Estado. Así, se supone que la ideología individualista defiende la libertad del ciudadano frente a la coacción estatal. Lo contrario, por lo tanto, a la existencia de tal libertad individual es la falta de la misma motivada por el ejercicio del poder estatal (el problema terminológico se complica cuando la falta de libertad individual se debe al ejercicio del poder no estatal, consecuencia inevitable cuando el primero, el poder estatal, se reduce por debajo de ciertos límites). El ejercicio de la libertad ciudadana da lugar a la sociedad civil. La simplificación ideológica contrapone tradicionalmente la imagen de una sociedad en la que predomine la sociedad civil, el libre mercado, el sistema de competencia, con aquella otra imagen en la que predomina el Estado, la planificación económica, la cooperación. «Derechas» e «izquierdas», respectivamente, han respondido a tales arquetipos ideológicos.

9 Sobre la importancia de la interación y de la experiencia en la construcción de modelos de la teoría de juegos y, en general, del individualismo metodológico, véanse F. Aguiar (1990) y J. Elster (1990).

${ }^{10}$ Véase el caso de la mafia en D. Gambetta (1990) o de los campesinos en T. Shanin (1983). 
Al igual que en el anterior nivel de análisis, se puede apreciar que los conceptos aludidos, el de sociedad civil y el de Estado, son complementarios e inseparables el uno del otro. No es posible la existencia por separado de cada uno de ellos. La sociedad civil es el resultado de aplicar la lógica individual en el comportamiento humano, mientras que el Estado aplica la lógica colectiva. Por muy planificado que pretenda ser un Estado, siempre emergerán estructuras espontáneas, imprevistas, efectos perversos, la búsqueda individual del propio beneficio, etc., compensando o deformando las pretensiones estatales iniciales. De la misma forma, la sociedad civil es impensable sin una autoridad estatal que imponga unas mínimas reglas del juego. La competencia, a diferencia del conflicto, exige un mínimo de acuerdo y coerción para existir.

La verdadera contraposición se da, por el contrario, en la explicación última (ideológica) que los teóricos del tema se han dado del problema de la colaboración humana: ¿por qué los hombres viven juntos, trabajan juntos, se organizan en colectividades? Caben dos respuestas a esta pregunta: la aristotélica y la iusnaturalista, siguiendo a N. Bobbio y N. Bovero (1986). La primera respuesta es que los hombres son sociales por naturaleza, es decir, vienen al mundo ya predispuestos a la sociabilidad; la segunda es que los hombres, seres individuales, llegan al convencimiento de que es mejor vivir juntos que separados y se ponen de acuerdo para ello. La primera es la tesis defendida, entre otros, por Aristóteles. De acuerdo con ella, en el principio de los tiempos fue el grupo familiar; de la unión de grupos familiares surgió la aldea; de la unión de aldeas y de grupos familiares surgieron las tribus; de la unión de las tribus, de aldeas y de grupos familiares surgieron finalmente las naciones ${ }^{11}$. La imagen construida por los iusnaturalistas es más abstracta, es decir, se aleja más del conocimiento de sentido común. Viene a decir que en un tiempo los individuos vivían solitarios, en total competencia (conflicto) por los recursos, y por ello están infrautilizados tales recursos. Toman conciencia de tal situación y deciden terminar con la misma mediante un contrato en el que se comprometen a perder soberanía individual en favor del Estado. A cambio reciben una organización colectiva que permite una situación de explotación más eficaz de los recursos. La situación posterior al contrato no consigue destruir por completo las tendencias individualistas de los sujetos, por lo que la situación social posterior al contrato estará formada por el Estado (formulado en el contrato) y la sociedad civil (los flecos no considerados en el contrato) ${ }^{12}$.

Es obvio que la contraposición entre Estado y sociedad civil sólo es posible

${ }^{11}$ Esta imagen ha tenido notable éxito entre los estudiosos del devenir humano. Véase R. L. Meek (1981). Por su parte, los defensores de la antropología evolucionista proponen el tránsito desde los "grupos domésticos» a las «tribus» y de éstas al Estado.

12 Como pone de manifiesto H. Marcuse (1983: 192), se trata seguramente de justificar metafísicamente la propiedad privada mediante toda esa construcción hipotética del contrato: «El proceso de transformar las relaciones entre los hombres en relaciones entre cosas opera en la formulación hegeliana. La persona está sumida en su propiedad y es una persona sólo en virtud de su propiedad. En consecuencia, Hegel denomina todo Derecho de Personas, Derecho de Propiedad.» 
dentro de una concepción contractualista de la sociedad, es decir, ambas son individualistas. Sólo la visión aristotélica es verdaderamente colectivista. Los nacionalismos y los fundamentalismos religiosos son manifestaciones ideológicas que se apoyan en tal concepción social de la naturaleza humana. Han llevado a su extremo el peso de la sociabilidad ${ }^{13}$.

\subsection{LA PERSONA: EL INDIVIDUO VERSUS LA COMUNIDAD}

Como se dijo arriba, la Sociología tiende a utilizar una noción simple de personalidad, cosa explicable dado que la personalidad corresponde a otro campo de estudio. La noción en cuestión es doble: en unos casos el sujeto es un actor con conciencia del "yo», que calcula costes y beneficios y toma decisiones siguiendo la lógica del máximo beneficio individual; en otros casos el sujeto es un actor que pertenece a algún grupo o categoría social propios de la estructura social, con conciencia del «nosotros», es decir, de pertenencia a tal grupo o categoría, y actúa guiado por la lógica del beneficio colectivo. En el primer caso se puede denominar al actor como "egoísta», y en el segundo como «altruista». Conviene, no obstante, matizar ambas nociones. En efecto, ambas tienen en común la aplicación de una racionalidad, de una lógica. Tal racionalidad consiste en la búsqueda del máximo beneficio, bien individualmente, bien colectivamente. En cualquier caso, siempre repercutirá en el actor, es decir, es posible la acción racional colectiva.

El que en unos momentos se tome una estrategia colectiva o, por el contrario, una estrategia individual para obtener tales beneficios no invalida en absoluto el carácter racional de la acción (adecuación a fines engarzados en un sistema coherente de preferencias). En último extremo y desde el punto de vista de la personalidad, un colectivo ha de ser definido como el conjunto de actores con intereses comunes (la clase social — «la clase en sí»- de Marx, o el grupo étnico o el religioso, por ejemplo) que optan por la estrategia colectiva para conseguir sus objetivos (conciencia de clase — "la clase para sí»—, siguiendo con el mismo ejemplo de Marx). Por supuesto que la conciencia del «nosotros» implica una conciencia de la existencia de intereses comunes, de rasgos comunes, de cierta cultura común. Tal conciencia de igualdad forma parte del análisis de costes de la puesta de acuerdo entre los distintos sujetos que forman el colectivo: cuanto más homogéneo, más fácil será la puesta en común de la acción individual o cooperación. Todo ello verdaderamente sin pérdida de la racionalidad e individualidad.

Frente a tal individuo racional, que opta según los casos por una estrategia colectiva u otra individual, se levanta el sujeto que pierde la noción de su "yo", que se diluye en un sentimiento comunitario. La comunidad sólo existe como

${ }^{13}$ El origen del individualismo como ideología, independizándose del colectivismo aristotélico, según Otto Gierke y L. Dumont, se encuentra en el individualismo cristiano. Véase L. Dumont (1987: 85). 
sentimiento (y como marco de referencia). Frente a la racionalidad del actor individual se encuentra la irracionalidad comunitaria. La comunidad sentida como «embriaguez». El sentimiento comunitario es efímero, transitorio. Por su parte, la individualidad es sentida como alienación, como pérdida. Es aquí en donde encaja nuestro discurso con los conceptos de «sagrado» (la comunión) y "profano" (la individualidad).

\section{Conceptos lógicamente contradictorios según niveles de análisis}

\begin{tabular}{lcc}
\hline & Individualismo & Comunitarismo \\
\cline { 2 - 3 } Sociedad & Acción & Relación \\
Cultura & Naturaleza individual & Naturaleza social \\
Personalidad & Individuo & Comunidad \\
\hline
\end{tabular}

\section{ACCIÓN SOCIAL VERSUS COMUNIÓN}

Existen, así pues y en primer lugar, tres niveles diferentes de análisis que no deben confundirse (el social, el cultural y el de la personalidad). En segundo lugar, nos encontramos con un conjunto de conceptos cuya base es la racionalidad, y otro conjunto de tales cuya base es la comunión irracional ${ }^{14}$. No hay que buscar la explicación de la preferencia de una u otra alternativa propia de un nivel concreto en la existencia de una u otra preferencia en un nivel distinto. $\mathrm{Ni}$ se debe dar el salto desde la racionalidad a la irracionalidad comunitaria buscando explicaciones de una en otra. Se trata en ambos casos de categorías lógicamente independientes. Sin embargo, no siempre se ha tenido esta precaución lógica. Los nueve conceptos diferentes aludidos han sido confundidos en muchas ocasiones, tanto mediante la asimilación de los correspondientes a la cooperación con los propios del comunitarismo, confundiendo los conceptos contrarios con los contradictorios; cuanto por la contraposición de conceptos falsamente opuestos por pertenecer a niveles de análisis distintos ${ }^{15}$.

A título de ejemplo de confusión a este respecto, conviene llamar la aten-

${ }^{14}$ Merece la pena recordar aquí la distinción que efectúa F. Nietzsche (1984) entre el carácter apolíneo, mesurado, autocontrolado, artificialmente refrenado, y el carácter dionisíaco, que pretende, mediante una actitud totalmente opuesta, sumergirse en la comunidad total, olvidarse del propio ego. Una lectura atenta de la primera parte de este libro (en la segunda desvaría un tanto) puede proporcionar las claves necesarias para interpretar los dos tipos de comportamiento, el apolíneo (racional) y el dionisíaco («ebrio»).

${ }^{15}$ La clásica distinción entre comunidad y sociedad de Tönnies adolece precisamente de múltiples confusiones, tal y como se ha puesto repetidamente de manifiesto. Así, el concepto de "comunidad» pertenece a un enfoque sociológico relacional, mientras que el de «sociedad» es propio de una teoría de la acción (K. D. Naegele); la "comunidad» es una realidad psicosocial, mientras que la «sociedad» goza de una presencia estructural objetivada (Gurvitch), etc. Véase al respecto B. Badi (1990). 
ción sobre la continuada tendencia a confundir la clase obrera o proletariado con una comunidad. Recordemos que se trata de conceptos pertenecientes a órdenes distintos: mientras la clase social es fruto de la toma de conciencia de intereses comunes (argumento totalmente racional), la comunidad es el resultado de la ofuscación de la individualidad, de la embriaguez del momento. En efecto, son múltiples las ocasiones en que se ha querido definir lo específico de tal clase dentro del lado «irracional» o dionisíaco de la tipología propuesta. Ocurre tal cosa, por ejemplo, en la distinción que B. Bernstein estableció entre lenguaje formal (propio de la racionalidad y de la individualidad, según nuestro criterio) y lenguaje público (propio de la comunidad), que se achacaron, respectivamente, a la clase media y a la clase obrera ${ }^{16}$. El fundamento último del denominado lenguaje público o de la actitud que le es propia (característico de la clase obrera) es la extraordinaria carga afectiva que le acompaña, según la idea de Bernstein y de sus seguidores.

Se produce la misma confusión también en los repetidos análisis sobre la capacidad de apreciación estética de cada una de las clases sociales, como en el caso de P. Bourdieu (1988). La clase "pudiente» manifiesta frente a lo estético una actitud distante, neutra; se preocupa por la forma más que por la función (contenido). El desapego, el distanciamiento estético es la clave de la apreciación artística de la clase alta. Por el contrario, la clase baja se «introduce» dentro de la manifestación artística; «sufre» con el protagonista; interpreta la obra de acuerdo con su ética, de acuerdo con el contenido. En una palabra, se emociona ante ella. Si no hay emoción, no hay arte para la clase baja. Precisamente los rasgos propios de la individualidad coinciden plenamente con la definición de apreciación estética de la clase alta, así como los de la clase baja son los propios de la irracionalidad comunitaria.

Ahora bien, dado que las observaciones empíricas sobre la materia arrojan gran cantidad de excepciones con respecto al comportamiento esperado, en una y otra clase social, hemos de pensar que es posible otro tipo de explicación diferente a la clasista. Ambos ejemplos, el del lenguaje y el de la apreciación estética, no invalidan en absoluto el análisis de clases sociales, sino que los reinterpretan de otra forma menos determinística ${ }^{17}$.

${ }^{16}$ Este tema merece más atención que la que aquí recibe. Véanse B. Bernstein (1964) y D. Lawton (1970), entre otros muchos autores. Todos ellos terminan por distinguir la «fuerte carga afectiva» que acompaña al lenguaje considerado de clase obrera. Las críticas posteriores a tal tipología lingüística se dirigieron al hecho de que el utilizar una u otra clase de lenguaje se debe al tipo de relación que en un determinado momento se mantiene: lo que verdaderamente diferenciaba a las clases sociales era la actitud ante el lenguaje, actitud mediatizada por la situación en la que tuviera lugar. Para una crítica contextual de lo anterior, véase W. Labov (1983).

${ }^{17}$ El proceso de socialización es la explicación que se encuentra a tales diferencias (las del lenguaje, las de la apreciación estética y cualquier otra que se base en la noción de subcultura de clase). Conviene recordar, no obstante, que todo individuo, con independencia de la clase a la que pertenezca, sufre una doble socialización. En primer lugar, la socialización primaria, caracterizada por la enorme carga afectiva que conlleva; de ahí el notable efecto de conformación que consigue. Después, la socialización secundaria, mucho más neutralmente afectiva y estrechamente 
Un sistema teórico que pretendiera comprender el comportamiento humano debería tener en cuenta todas las categorías arriba expuestas, tanto las racionales como las de irracionalidad comunitaria; tanto unos niveles como otros. Sin embargo, parece difícil lograr tamaña comprensión. Los modelos que encajan en lo que se ha dado en llamar teoría de la acción parecen explicar convincentemente el comportamiento propio de la racionalidad, entendiendo por tal mucho más de lo que el sentido común estimaría por racional. Ya esta teoría de la acción se aleja extraordinariamente de lo que las ciencias de la naturaleza entienden por "teoría", puesto que ha de partir de la existencia de un sujetoobjeto intencional. Pese a tal alejamiento, la teoría de la acción constituye el sistema teórico marco más elaborado y "duro» dentro de la Sociología, y es así gracias precisamente a contar con un sujeto-objeto que actúa intencionalmente. La falta de un axioma «útil», semejante, en el área de la irracionalidad comunitaria es lo que ha impedido el desarrollo de otro sistema teórico elaborado. Apenas se ha esbozado una teoría de la relación comunitaria, ni tiene visos de que así sea. Su propio objeto de estudio, la "comunión irracional», favorece un tratamiento teórico «blando», opinable y ensayístico ${ }^{18}$.

\section{TIPOS DE MODELOS DE ACOPLAMIENTO ENTRE LA ACCIÓN RACIONAL Y LA RELACIÓN COMUNITARIA}

El desarrollo de una teoría de la relación comunitaria solamente es posible si se hace a la par que la teoría de la acción racional, ya que ambas cobran sentido al unísono. De ahí que hayan sido muy numerosos los intentos realizados para lograr el ensamblaje entre la tradición colectivista y la individualista ${ }^{19}$, pese a las dificultades que tal operación conlleva, como se ha puesto de manifiesto a lo largo de las páginas anteriores. Por su parte, estos intentos de ensamblaje pueden ser agrupados en dos categorías generales que merecen ser repasadas: los modelos de suma cero y los modelos compensatorios ${ }^{20}$.

ligada a las tareas relacionadas con la división social del trabajo. Véase, por ejemplo, P. Berger y Th. Luckmann (1986: 164 y ss.).

${ }_{18}$ Éste es el caso, por ejemplo, de M. Maffesoli (1990).

19 Para un repaso de los planteamientos individualistas y colectivistas, confundiendo los dos matices (cooperación-comunión) dentro del colectivismo, en los orígenes del pensamiento sociológico, véase T. Parsons (1961).

${ }^{20}$ Se podría añadir una tercera categoría apenas utilizada por los sociólogos y que se desprende de la obra de Nietzsche ya citada, El origen de la tragedia. Según tal planteamiento, la distinción entre comportamiento racional y comportamiento comunitario sería el grado de templanza. Así, es propio del carácter apolíneo (racional) la mesura, el autocontrol, seguir el criterio de «nada en exceso", etc. Frente a él, el carácter dionisíaco (comunitario) es pasional, arrebatado, se siente en estado de embriaguez. Según esto, no habría dos clases de comportamiento, sino una sola con diferentes grados de irracionalidad. 


\subsection{MOdelos de suma Cero}

Encajan dentro de esta categoría todas aquellas interpretaciones del cambio social en las que la progresión de la racionalidad se realiza a costa de la relación comunitaria. Por la misma razón, en aquellas otras sociedades en las que el comportamiento es predominantemente comunitario no caben comportamientos de tipo racional. En otras palabras, se trata de comportamientos incompatibles: cada paso dado en la dirección de la modernidad supone dejar atrás otro tanto de comportamiento comunitario. A su vez, estos modelos de suma cero pueden ser clasificados en dos subcategorías: los lineales y los cíclicos.

\subsubsection{Modelos lineales de suma cero}

Este tipo de modelos de cambio social es el propio de la Ilustración del siglo XVIII, o de la idea de progreso del siglo XIX, o de la idea de modernidad del siglo XX. De acuerdo con ellos, el río profundo de la historia lo constituye un tránsito inevitable, aunque lento, hacia una sociedad guiada por la racionalidad y exenta de irracionalismo comunitario. En el trasfondo de tal sociedad se mueve el hombre libre, racional y, por tanto, igual a todos los demás hombres. Las demandas de diferenciación, el derecho a ser diferentes, no son sino manifestaciones de la irracionalidad comunitaria que poco a poco irán desapareciendo. J. J. Sebreli (1992) ofrece una visión ideal típica de este tipo de modelos, así como también la mayor parte de los trabajos sociológicos sobre la modernidad —véanse S. N. Eisenstadt (1992) o G. Germani (1992)— y la teoría antropológica evolucionista.

Los citados modelos lineales de suma cero se apoyan también en una interpretación historicista y literal de los diferentes modelos de sociedad de la teoría clásica: Tönnies («sociedad» y «comunidad»), Durkheim (sociedades unidas por «solidaridad mecánica» y sociedades unidas por "solidaridad orgánica»), Redfield («sociedades folk» y «sociedades urbanas»), Becker («sociedades sagradas» $\mathrm{y}$ «sociedades seculares»), Meine (sociedades unidas por la «hermandad» y sociedades unidas por la "competición»), etc. La interpretación histórica de todos ellos supone el tránsito desde una sociedad tradicional a otra moderna. Como luego veremos, es posible otro tipo de interpretación de los mismos.

\subsubsection{Modelos cíclicos de suma cero}

Al igual que en el caso anterior, la racionalidad se gana a expensas de la irracionalidad comunitaria; $y$, a la inversa, cuando gana terreno la irracionalidad comunitaria lo hace porque lo pierde la racionalidad. Sin embargo, la diferencia entre ambos tipos radica en que, según los modelos cíclicos, no hay un 
desenlace racional inevitable, sino que se producen constantes oscilaciones desde uno a otro extremo del comportamiento humano: la historia está constituida por una sucesión de ciclos, alternancias entre uno y otro tipo de comportamientos.

El fundamento último de la idea de ciclo se encuentra en la concepción circular del cambio social, en el "mito del eterno retorno". Como paradigma del cambio cultural cíclico merece recordarse a P. A. Sorokin (1962) cuando distingue dos extremos del ciclo: la sociedad "sensible», o que utiliza los sentidos (la observación) como criterio de validez, y la sociedad «ideativa», que como criterio de validación se vale de la fe. Muy ligados a esta concepción del cambio social se encuentran los estudios sobre la moda y la distinción (desde Tarde a P. Bourdieu). La dialéctica «modernidad» versus "postmodernidad» puede ser interpretada en términos cíclicos.

\subsection{MODELOS COMPENSATORIOS}

Según este tipo de modelos, en cualquier sociedad, ya sea tradicional o moderna, un avance en el comportamiento racional ha de ser compensado con algún gesto comunitario que contrarreste la disgregación social que aquél supone. Es decir, con independencia de la etapa histórica en la que se encuentre una sociedad, siempre encontraremos la misma proporción de comportamientos racionales y comportamientos comunitarios, so pena de generación de conflictos. Son, por lo tanto, modelos que interpretan la relación entre el comportamiento racional y el comunitario en términos de equilibrio.

Tales modelos compensatorios proceden en gran medida de una interpretación ahistórica de los tipos de sociedad «moderno" y "tradicional» a los que anteriormente se hacía referencia. En particular, proceden de la interpretación no literal de la obra de Durkheim por parte de muchos de sus seguidores, siguiendo las indicaciones que parecen desprenderse de las últimas obras del citado autor ${ }^{21}$.

Pertenecen a esta categoría obras tan variadas como la posterior de B. Bernstein (1988) (véase en particular el tercer capítulo, titulado "Ritual en la educación», pp. 53-64), que distingue el "comportamiento instrumental» del "comportamiento expresivo» en el aula; la de R. Dahrendorf (1983), al diferenciar entre «libertad» e «integración», buscando de paso el punto de compromiso entre la "libertad» individual y la "necesidad de integración»; la de V. W. Turner (1988) y su estudio sobre los ritos ${ }^{22}$, etc. Seguramente, este tipo com-

${ }^{21}$ Véanse, por ejemplo, los trabajos que forman el texto compilado por J. C. Alexander (1989).

22 Una de las fórmulas de acceso al comportamiento irracional comunitario es el análisis de los rituales. En este sentido es paradigmático el texto de V. W. Turner (1988), en particular su capítulo III, pp. 101-136, titulado "Liminalidad y communitas», en el que relaciona la estructura social emanada de la división social del trabajo, profundamente desigualitaria, y el sentimiento 
pensatorio de modelos de ensamblaje entre la individualidad y la colectividad puede explicar gran parte de los conflictos propios de la sociedad moderna. Ahí radica el renovado interés que parece descubrirse en la sociología actual por nuestro clásico Emilio Durkheim²3.

\section{CONCLUSIONES}

Se ha ido elaborando a lo largo del texto una compleja tipología de elementos que componen la realidad social. Tal tipología está formada por conceptos afines al individualismo, sus complementarios y sus contradictorios. Asimismo, esos conceptos se despliegan en los tres niveles clásicos del análisis sociológico: el social, el cultural y el de la personalidad. La explicación y comprensión de cualquier aspecto del comportamiento humano debe presuponer la utilización de la tipología completa. Y ahí es donde surgen los dos problemas básicos del tratamiento propuesto: $a$ ) en principio, no es posible, desde un punto de vista lógico, compaginar los conceptos afines al individualismo, con sus contrarios y sus contradictorios, en un mismo modelo teórico; $b$ ) además, estamos tratando con estructuras de geometría variable, ya que la proporción de los elementos afines, contrarios y contradictorios varía según las circunstancias. Cuando se habla de la particularidad de la lógica de lo social, en realidad estamos refiriéndonos a estas dos posibilidades tan atípicas.

J. C. Alexander (1995: 11-26) proporciona una clasificación, muy semejante a la nuestra, de lo que él llama presuposiciones generales (presupuestos filosóficos) de todo modelo sociológico. Utiliza dos dimensiones: racionalidad versus irracionalidad y colectivismo versus individualismo. Cualquier teoría que quiera explicar el comportamiento humano debe prever las cuatro posibilidades resultantes de cruzar esas dos dimensiones. Según este autor, los diferentes intentos teóricos habidos hasta la fecha han fracasado por partir exclusivamente de una sola presuposición general, excluyendo las restantes. Esto ha conducido a los teóricos sociales a la necesidad de utilizar categorías residuales que les permitan acceder a comportamientos reales no previsibles desde su planteamiento teórico original, pero que no son otra cosa que indicadores del fracaso de la unidimensionalidad de sus respectivas teorías. J. C. Alexander propone un tipo de enfoque multimensional, basado en el desarrollo de la teoría de

de comunidad basado en una total homogeneización de los elementos de tal comunidad. Ese sentimiento se exterioriza en el momento del ritual que denomina «fase liminal» (siguiendo a A. van Gennep) y supone un fuerte rechazo, aunque efímero, de la desigualdad social. Según este autor, los ritos de paso, en particular, constituyen una ligazón manifiesta entre los sentimientos comunitarios y la pertenencia a la estructura social. La «fase liminal» reúne las características propias del comportamiento comunitario: igualdad, totalidad, homogeneidad, anonimato, obediencia total...

${ }^{23}$ Sobre los autores cuya obra se inspira en semejantes planteamientos durkheimianos pero que no reconocen explícitamente tal inspiración, véase J. C. Alexander (1988: 1-22, «Introduction: Durkheimian sociology and cultural studies today»). 
T. Parsons, cuya obra, según el propio Alexander, es la que más se acerca al ideal de multidimensionalidad.

El razonamiento de Alexander pone en evidencia la dificultad de manejar conceptos contrarios y contradictorios dentro de un único modelo teórico. La respuesta que se propone desde nuestro trabajo no es tanto la búsqueda de un enfoque teórico multidimensional comprensivo cuanto la toma de conciencia de esa multidimensionalidad en el comportamiento humano. Esta toma de conciencia de la realidad permite echar mano, de manera pragmática, de diferentes modelos teóricos específicos para explicar distintos aspectos particulares de un mismo comportamiento humano. Dando por supuesto que ninguno de tales modelos puede agotar la explicación de ese comportamiento. Queda, sin embargo, una laguna por rellenar. No se ha elaborado todavía un modelo teórico satisfactorio que dé cuenta del conjunto de conceptos que conforman la parte irracional del acontecer social.

Por su parte, el análisis de la geometría variable de la estructura plantea problemas más graves aún. La proporción de racionalidad e irracionalidad en el comportamiento humano varía según las circunstancias, al igual que varía la proporción de racionalidad individual y de racionalidad colectiva. El modelo teórico que por ahora mejor parece acomodarse a tal variabilidad es el que se deriva de la Teoría general de sistemas, más concretamente el que se deduce de lo que N. Luhmann (1998: 31-57) llamó teoría de la diferenciación de los sistemas. Procesos tales como identificación y diferenciación se consiguen mediante la delimitación constante y variada del sistema y su entorno. El proceso surge y se dirige desde dentro del propio sistema (sistemas autorreferenciales). Aunque la idea de Luhmann es muy sugerente, parece encajar muy mal con la clasificación aquí utilizada, concretamente con las categorías de sociedad, cultura y personalidad. Pero todo eso es ya otro asunto.

\section{BIBLIOGRAFÍA}

Aguiar, F. (1990): «Lógica de la cooperación», en Rev. Zona Abierta, 54/55, pp. 7-42.

AleXAnder, J. C. (1989): Durkheimian sociology: cultural studies, Los Angeles, University of California.

- (1995): Las teorías sociológicas desde la segunda guerra mundial, Barcelona, Gedisa.

BADI, B. (1990): "Community, Individualism, and Culture», en P. Birnbaum y J. Leca (eds.), Individualism. Theories and Methods, Oxford, Clarendon Press, pp. 95-115.

Berger, P., y Luckmann, Th. (1986): La construcción social de la realidad, Madrid, Amorrortu.

Bernstein, B. (1964): «Aspects of Language and Learning in the Genesis of the Social Process», en D. Hymes (comp.), Language, in Culture and Society, Nueva York, Harper, pp. 251-263.

- (1988): Clases, códigos y control. II. Hacia una teoría de las transmisiones educativas, Madrid, Akal.

Birnbaum, P., y Leca, J. (1990): «Introduction», en P. Birnbaum y J. Leca (eds.), Individualism. Theories and Methods, Oxford, Clarendon Press, pp. 1-90.

Bobbio, N., y Bovero, N. (1986): Sociedad y Estado en la filosofía moderna, Méjico, FCE.

Boudon, R. (1979): Effets pervers et ordre social, París, PUF.

- (1981): La lógica de lo social, Madrid, Rialp. 
Bourdieu, P. (1988): La distinción. Criterio y bases sociales del gusto, Madrid, Taurus.

DAHrendorf, R. (1983): Oportunidades vitales, Madrid, Espasa-Calpe.

DumOnT, L. (1987): Ensayos sobre el individualismo, Madrid, Alianza.

EISENSTADT, S. N. (1992): «Estudios de modernización y teoría sociológica», en T. Abat Carnero (ed.), Modernización, desarrollo politico y cambio social, Madrid, Alianza, pp. 35-70.

ElSTER, J. (1990): «Racionalidad, moralidad y acción colectiva», en Rev. Zona Abierta, 54/55, pp. 43-68.

Gambetta, D. (1990): «La mafia: el precio de la desconfianza», en Rev. Zona Abierta, 54/55, pp. 137-166.

Gellner, E. (1990): "The Gaffe-Avoiding Animal or A Bundle of Hypotheses», en P. Birnbaum y J. Leca (eds.), Individualism. Theories and Methods, Oxford, Clarendon Press, pp. 17-32.

Germani, G. (1992): "Secularización, modernización y desarrollo económico», en T. Abat Carnero (comp.), Modernización, desarrollo político y cambio social, Madrid, Alianza, pp. 71-100.

Jasay, A. de (1989): Social Contract Free Ride. A Study of the Public Goods Problem, Oxford, Clarendon Press.

LaboV, W. (1983): Modelos sociolingüisticos, Madrid, Cátedra.

LAWTON, D. (1970): Social Class, Language and Education, Londres, Routledge and Kegan.

LuHmann, N. (1998): Sistemas sociales. Lineamientos para una teoría general, Barcelona, Anthropos y otros.

Maffesoli, M. (1990): El tiempo de las tribus. El declive del individualismo en las sociedades de masas, Barcelona, Icaria.

MarCuSE, H. (1983): Razón y revolución, Madrid, Alianza.

MEeK, R. L. (1981): Los orígenes de la ciencia social. El desarrollo de la teoría de los cuatro estadios, Madrid, Siglo XXI.

NiETzSChe, F. (1984): El nacimiento de la tragedia (1.a ed., 1871), Madrid, Alianza.

PARSONS, T. (1961): "The General Interpretation of Action», en T. Parsons, K. D. Naegele y J. R. Pitts (comps.), Theories of Society. Foundations of Modern Sociological Theory, Nueva York, The Free Press, pp. 85-97.

PinO ARTACHO, J. del (1990): La teoría sociológica. Un marco de referencia analítico de la modernidad, Madrid, Tecnos.

RODRíGUEZ IBÁÑEZ, J. E. (1991): «Decisión racional versus holismo: ¿Una teoría estratégica integral de la acción colectiva?», en REIS, 54/91, pp. 21-50.

Sebreli, J. J. (1992): El asedio a la modernidad. Crítica del relativismo cultural, Barcelona, Ariel.

SHANin, T. (1983): La clase incómoda, Madrid, Alianza.

SOROKIn, P. A. (1962): Dinámica social y cultural, Madrid, Instituto de Estudios Políticos.

TURNER, R. H. (1991): «Usos acertados y erróneos de los modelos racionales para la conducta colectiva y la psicología social», en T. González de la Fe (coord.), Sociología: unidad y diversidad, Madrid, CSIC, pp. 143-175.

TURner, V. W. (1988): El proceso ritual, Taurus.

\section{ABSTRACT}

The dilemma individualism versus collectivism is one among the many dilemmas which we find in the making of a social map. To highlight the complexity which this dilemma involves, we have devised a set of concepts arranged around the idea of individualism in the three traditional levels of sociological analysis: the social one, the cultural one and the one related to personality. In each of these levels we have also to find the concepts which are complementary and contradictory to the strictly individualistic ones, thus giving rise to a complex and useful conceptual classification. 